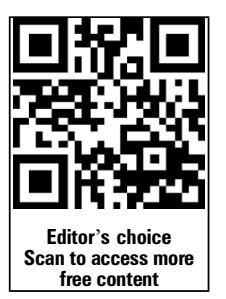

Correspondence to

Dr Joshua May, Philosophy, University of Alabama at Birmingham, 900 13th Street South, HB 425, Birmingham 35294-1260, USA; joshmay@uab.edu

Received 20 February 2015 Revised 4 September 2015 Accepted 2 October 2015 Published Online First 23 October 2015

CrossMark

To cite: May J. J Med Ethics 2016:42:26-30.

PAPER

\title{
Emotional reactions to human reproductive cloning
}

Joshua May

\begin{abstract}
Background Extant surveys of people's attitudes towards human reproductive cloning focus on moral judgements alone, not emotional reactions or sentiments. This is especially important given that some (especially Leon Kass) have argued against such cloning on the ground that it engenders widespread negative emotions, like disgust, that provide a moral guide.
\end{abstract}

Objective To provide some data on emotional reactions to human cloning, with a focus on repugnance, given its prominence in the literature.

Methods This brief mixed-method study measures the self-reported attitudes and emotions (positive or negative) towards cloning from a sample of participants in the USA.

Results Most participants condemned cloning as immoral and said it should be illegal. The most commonly reported positive sentiment was by far interest/curiosity. Negative emotions were much more varied, but anxiety was the most common. Only about a third of participants selected disgust or repugnance as something they felt, and an even smaller portion had this emotion come to mind prior to seeing a list of options.

Conclusions Participants felt primarily interested and anxious about human reproductive cloning. They did not primarily feel disgust or repugnance. This provides initial empirical evidence that such a reaction is not appropriately widespread.

\section{INTRODUCTION}

It is well known that the public tends to disapprove of human reproductive cloning. Nisbet reports that a majority of people in the USA, polled between 1993 and 2002, tends to disapprove of reproductive cloning (and slightly approve of some therapeutic uses). ${ }^{1}$ Shepherd et $a l^{2}$ found similar attitudes in the UK (polled between 2004 and 2005). They report negative opinions on average towards the reproductive cloning of human beings, although with some slight support of it in 'certain circumstances'. More recently, Gallup reports in 2014 that only $13 \%$ of Americans believe cloning human beings is generally 'morally acceptable'. ${ }^{3}$

However, there are no data on people's emotional reactions specifically. This is important to address at least because some influential theorists insist that we take seriously our intuitive emotional reactions towards issues in bioethics. Leon Kass has famously asserted that 'repugnance is the emotional expression of deep wisdom, , and he applies this specifically to human cloning: 'We are repelled by the prospect of cloning human beings... because we intuit and we feel, immediately and without argument, the violation of things that we rightfully hold dear'. 5 In various pieces, Kass describes human cloning for reproductive purposes as revolting, grotesque, repugnant and Frankensteinian. He urges us to ban the cloning of human beings, as it is a 'clear fork in the road' where the wrong choice could lead us into a dystopian 'Brave New World'.

Kass is not the only disgust advocate (to borrow a term from Kelly ${ }^{6}$ ). Some fellow conservative theorists believe reactions of disgust have an important role to play in moral and political discourse (eg, $\mathrm{Kekes}^{7}$ ), and liberals have also made similar claims $\left(\mathrm{eg}, \operatorname{Kahan}^{8}\right)$. Not all of these thinkers agree about the exact role of disgust or about the morality of particular bioethical issues. Indeed, only Kass focuses so intently on human cloning as the point of no return. However, they all agree that there is some wisdom in repugnance. This line of argument is especially important to evaluate since it can influence policy decisions about cloning and other biotechnologies.

Disgust sceptics have raised serious challenges, but they are decidedly normative. Nussbaum, ${ }^{9}$ for example, argues that reactions of repugnance are morally unreliable, and Pence ${ }^{10}$ charges that by default, such reactions should be regarded with suspicion in ethics unless we find reason to think otherwise. An underlying assumption among disgust advocates, however, is wholly empirical. They must assume that this emotional reaction, which is meant to provide moral guidance, is prominent and widespread among ordinary people. Kass is well aware of this, referring to 'the widespread repugnances of humankind' that one can allegedly find 'from the man or woman in the street and from the intellectuals, from believers and atheists, from humanists and scientists' (19). Likewise, what John Kekes labels 'moral disgust' is 'profound' and 'instinctive'-not a mere 'matter of taste'. It responds to the behaviour that 'just about everybody in contemporary Western societies would find disgusting' (102). While he is well aware that some individuals may not have such reactions, Kekes believes that disgust is 'the normal reaction' to the relevant actions, such that 'its absence requires further explanation' (103).

A second assumption of disgust advocates is that this emotion substantially influences the relevant moral judgements. Otherwise, the idea would be more akin to saying that we should take seriously the mental fatigue we experience when contemplating bioethical issues like human cloning. While mental fatigue may slightly influence moral judgements, ${ }^{11}$ it is unclear whether we should take its 'wisdom' seriously if it does not substantially determine whether we think something is right or wrong. Some recent experimental evidence might 
seem to confirm this second assumption, ${ }^{12}{ }^{13}$ but there is reason to doubt that the influence is substantial. ${ }^{14} 1516$ Incidental feelings of disgust at best sometimes make moral judgements slightly more harsh, but only if one already believes the relevant action is immoral. The presence or absence of disgust, like mental fatigue, does not reliably lead people to change their moral opinions. Appeals to repugnance, though, are meant to provide reason to believe something is morally questionable, not evidence that one already believes it. ${ }^{17}$

Our focus, at any rate, will only be on the first assumption, concerning how widespread reactions of repugnance are to human cloning. I thus conducted a brief study to examine the emotional reactions people have towards human (reproductive) cloning with special attention to whether disgust is prevalent. The results are a bit mixed but do not strongly support the first empirical assumption made by Kass and similar theorists. Of the basic negative emotions one might feel towards human cloning, only a minority of participants in my sample reported feeling disgust or repugnance. Other emotions were instead more widespread, particularly interest or curiosity and anxiety.

\section{METHOD}

A straightforward methodology involves mixing quantitative and qualitative methods, asking participants to self-report their reactions to cloning on a web-based survey. So that participants knew the same basic facts of human reproductive cloning, I employed the following background text (226 words), adapted from previous survey research on the topic:

Please read the following information carefully. You will be asked questions about it later.

You might have heard of something called "human cloning." Using such a process, one could create a child that shares nearly the exact same genetic makeup as someone else. The genes from this "donor" would be copied and used to make an embryo. The donor could be the woman who gives birth to the child, but it could also be a celebrity or even a stranger.

Various people might be interested in this process of reproductive cloning, such as an infertile couple. But a couple or an individual without fertility problems may also be interested. What makes this sort of cloning different from other forms of assisted reproduction already in use (such as IVF) is that it allows more control over the genetic makeup of the child. One could choose to have a child with the genes of a particular celebrity or Nobel prize winner. Or one could just choose to copy the genetic makeup of a loved one in the family, perhaps someone who passed away at an early age.

We're interested in what moral sentiments you have toward this sort of human cloning, in which a child is purposely made to have nearly the exact same genes as another person. We'll ask you a total of 8 questions about this.

On reading this prompt, the participants were asked to answer an initial three questions presented on the same page. The first two concerned whether they thought such cloning: (1) should be illegal, (2) is morally wrong. The responses were recorded on a Likert-type scale $(1=$ Definitely No; $7=$ Definitely Yes). The final item on the first page asked participants to: (3) 'please list any emotional reactions you have toward such cloning, whether positive or negative, that quickly come to mind'. This open-ended response item provided an opportunity for subjects to report what they felt immediately after reading about cloning and without being biased by a preset list of choices about what to feel. In particular, I aimed to determine how many participants would describe their reactions using the term 'disgust' or synonymous words (in particular, repulsive, grotesque, gross, sick, disgust, eww or creepy).

On the next page, the remaining five questions were presented. First, participants were asked to (4) 'please select any of the following negative emotional reactions you have toward such cloning'. The options (presented in random order) were based roughly on the basic negative emotions identified by Plutchik ${ }^{18}$ that would be relevant in this context: (a) fear, (b) sadness, (c) anger, (d) disgust or repugnance, (e) anxiety or (f) none in this list. Question (5) then asked: 'Of the negative emotions, which is most prominent (as best you can tell)?'

The second set of questions concerned positive emotions. (6) 'Please select any of the following positive emotional reactions you have toward such cloning'. Again, the following list was based roughly on Plutchik: (a) pleasure or joy, (b) excitement, (c) comfort or trust, (d) amusement, (e) interest or curiosity, (f) none in this list. As with the negative emotions, participants were prompted with: (7) 'Of the positive emotions, which is most prominent (as best you can tell)?'

Finally, participants were allowed to provide any feedback on the survey. They were specifically encouraged to identify any emotions they felt towards human reproductive cloning that were not on the lists. This item was included to check whether unexpected reactions emerged that were missing from the preset lists. Such responses would be approached by identifying words that do not match the preset lists or their synonyms.

Subjects were recruited on Amazon's Mechanical Turk website, now commonly used by social scientists for completing tasks electronically. ${ }^{19}$ Only users accessing the site within the USA could participate, and each received US $\$ 0.50$ for about 35 min spent filling out the survey on Qualtrics. No inferential statistics were planned, since the aim of this study is merely to provide some descriptive data on emotional reactions towards cloning, as opposed to experimental manipulation of variables. A substantial sample size of 250 was sought, as at least 200 could estimate the American population at 95\% CIs with a margin of error of $7 \%$, assuming a normal distribution.

\section{RESULTS}

Twenty-four participants did not fully complete the survey once started, leaving 226 responses. Many in the sample found human reproductive cloning morally problematic (see table 1). While the mean and median are near the midpoint, which suggests ambivalence on average, the distribution of responses reflects disagreement. Concerning both legality and morality, the most common response was that human cloning is definitely immoral and should definitely be illegal. However, this represented only a minority of the sample (about $22 \%$ in each case). As with many hotly debated ethical issues, there is much disagreement.

Prior to seeing a list of emotions, only a handful of participants reported feeling no emotions towards cloning. Not many

Table 1 Responses to moral and legal status of human cloning

\begin{tabular}{lllllll}
\hline & Mean & Median & Mode & $\begin{array}{l}\text { Yes } \\
(\%)\end{array}$ & $\begin{array}{l}\text { No } \\
(\%)\end{array}$ & $\begin{array}{l}\text { Unsure } \\
(\%)\end{array}$ \\
\hline $\begin{array}{l}\text { Should be } \\
\text { illegal? }\end{array}$ & $4.14(\mathrm{SD}=2.16)$ & 4.0 & 7.0 & 43 & 41 & 16 \\
Is immoral? & $4.27(\mathrm{SD}=2.15)$ & 4.0 & 7.0 & 47 & 37 & 16 \\
\hline
\end{tabular}

7-point scale, 1=Definitely No and 7=Definitely Yes $(\mathrm{N}=226)$. 
Table 2 Frequency of self-reported emotions

\begin{tabular}{lllc}
\hline Negative & Per cent & Positive & Per cent \\
\hline Anxiety & 44.7 & Interest/curiosity & 67.7 \\
Fear & 31.9 & Excitement & 24.3 \\
Disgust/repugnance & 31 & Amusement & 14.6 \\
Sadness & 19.9 & Pleasure/joy & 8 \\
Anger & 14.2 & Comfort/trust & 4.9 \\
None of these & 28.3 & None of these & 26.5 \\
\hline
\end{tabular}

reactions to this free response item were especially common, although interest, fear and anxiety were quite frequently reported. Only 26 participants described their reactions using the word 'disgust' or its synonyms. These 26 responses represent only $11.5 \%$ of the entire sample and only $24 \%$ of the subset who thought human cloning is immoral (ie, the 107 participants who provided a response on the morality scale greater than 4).

When given emotions to select from a list, the most common negative emotion was anxiety, with almost half of participants selecting this as something they felt towards cloning. Disgust tied with fear as the second most commonly self-reported emotion, but this comprised just under a third of those in the sample; about an equal proportion chose 'none' of the emotions in the list (see table 2). Looking only at those who condemned cloning as immoral, however, 59\% chose 'disgust or repugnance' from the list.

Of the most prominently felt emotions, a clear majority selected Interest/Curiosity from the positive list (see table 3). Anxiety was the most commonly selected negative emotion, but it did not represent a large majority of the sample. Interestingly, disgust was almost as frequently selected as prominent among the negative emotions, but this still represented only one-fifth of the sample. However, among the 107 who thought cloning is immoral, 39\% selected 'disgust or repugnance' as most prominent.

Of the open responses to the final question, only three participants identified any emotions felt that were not on the list or clear synonyms (namely, hope, surprise and pride). It appears that those who selected the 'none' options were most often indicating that they did not feel any emotions of the relevant type (positive or negative) or perhaps that none were prominent (in response to questions 5 and 7).

\section{DISCUSSION}

The data on moral attitudes towards cloning are roughly consistent with previous research (eg, Nisbet 2004), indicating that most disapprove of it. However, it is perhaps curious that those

Table 3 Proportion of participants selecting the emotion as 'Most Prominently Felt'

\begin{tabular}{lllc}
\hline Negative & Per cent & Positive & Per cent \\
\hline Anxiety & 26.5 & Interest/curiosity & 60.6 \\
Disgust & 19.9 & Excitement & 8.4 \\
Fear & 16.4 & Amusement & 3.5 \\
Sadness & 8.4 & Comfort/trust & 1.8 \\
Anger & 1.8 & Pleasure/joy & 0.4 \\
None of these & 27.0 & None of these & 25.2 \\
\hline
\end{tabular}

opposed do not represent a strong majority. A recent Gallup poll, in particular, indicates that only $13 \%$ of Americans think human cloning generally is morally acceptable. However, first, that poll did not explain human cloning to participants. So, greater acceptability of the practice in my sample may well be due to the clear explanation of cloning provided, which does some work to dispel common myths about clones being, say, mindless drones used to harvest organs. Second, my participants were provided a scale with a midpoint to register ambivalence, rather than given a forced choice between morally 'acceptable' or 'not'. And, as we can see, about $16 \%$ were unsure about the moral status of cloning, and even more, only deviated slightly from the midpoint, indicating a position on the issue, but lacking much confidence. The moral attitudes we find here towards human cloning match much more closely to those found in other studies employing more fine-grained measures and explanatory stimuli.

The data indicate a diversity of emotional reactions towards human reproductive cloning. However, among positive emotions, interest or curiosity dominated. Among negative emotions, anxiety was most commonly selected, but disgust, fear and sadness were close behind. In this way, the negative emotions were much more diverse and divided across the sample.

\section{Ethical implications}

What can these data on emotional reactions tell us about the morality of human reproductive cloning? To date, the literature has focused on the emotion of disgust. The results, however, do not speak much in favour of the basic empirical assumption in the argument from repugnance against human cloning, as the reaction of disgust does not appear to be widespread. Kass and similar theorists are not entirely idiosyncratic in their reactions of disgust, but only a very small portion had this emotion immediately come to mind (11.5\%), and only one-third (31\%) selected it from a list.

Perhaps it is unsurprising that many in the sample did not feel disgust because over half were either unsure of its moral status or thought it was probably permissible. When we examine the self-reported emotions of only those who condemned cloning, we find a much larger proportion reporting disgust or repugnance. However, there are at least three reasons why this does not necessarily support an argument from disgust.

First, even if we do just focus only on those participants who condemned human cloning, disgust is not exactly widespread. Only about a quarter (24\%) mentioned disgust or similar terms prior to seeing a list of optional emotions to select, and only a minority (39\%) believed it was most prominent of the negative emotions they felt. Of course, when it appeared in a list, a majority (59\%) selected 'disgust or repugnance' as something they felt. But this is not an especially large majority, even among those who think cloning human beings is immoral.

Second, and more important, it is not enough that disgust arises in a slight majority of those who already oppose human cloning. This would yield a rather different argument, which implores us to take seriously as a moral guide a reaction that many of us do not have. Since disgust advocates point to the emotion as a way of arguing for a position on the issue-especially as a way of convincing those who are unsure or 'on the fence'-disgust should presumably show up in many opponents of cloning and in those indifferent to it. Such a premise is required for an argument of the form: take your reaction of repugnance as evidence that there is something wrong with this practice. And the problem remains if one were to argue that these data simply provide evidence that the disgust reaction 
towards cloning has already lost its footing, as our desensitised society travels down the slippery slope into dystopia. That would concede that arguments against cloning cannot rest on 'our' current reaction of disgust as a moral guide, as it effectively abandons the argument from disgust.

Finally, participants were presented with a rather inclusive category: 'disgust or repugnance'. Yet reporting disgust, and especially repugnance, may sometimes merely be a way of signalling a negative judgement, such as moral condemnation, rather than the distinct emotion of visceral disgust. ${ }^{152021}$ We cannot settle the issue here, but it is important for assessing arguments that appeal to the alleged wisdom of repugnance, since the argument would be circular if the term 'repugnance' is just meant to be synonymous with 'wrong'. Rightly, Kekes says that to say a certain behaviour is 'sickening is not a metaphor' (101). This survey, unfortunately, cannot clearly distinguish literal uses of 'disgust' from more loose senses of the term, but it is possible some reported feeling 'disgust' only to signal their moral disapproval.

Putting these three problems together, the data do call into question an empirical assumption in the argument from disgust. First, while a slight majority of participants who already reject human cloning as wrong report feeling repugnance towards it, some in this group may have been simply treating the terms 'disgust' or 'repugnance' as meaning that they disapprove of the practice. Second, the argument from disgust relies on more than the premise that those already opposed to human cloning feel disgust towards it; the idea is that it should be rather widespread among even those on the fence or in favour of it. Finally, if we do then examine the frequency of self-reported disgust among all participants, again, only a minority (31\%) selected it from the list and even fewer reported feeling it prior to seeing a list of options (11.5\%).

Perhaps disgust advocates could instead argue that the intuitive reaction we should respect is not necessarily disgust but rather a general negative moral intuition. There is mounting scientific evidence for the prevalence of moral intuitions, conceived as immediate pretheoretical reactions. A key researcher in this area, Jonathan Haidt, ${ }^{22}$ explicitly cites Kass as being the 'foremost spokesman' for intuitions having to do with sanctity or divinity (351). A general intuitive disapproval of cloning is arguably widespread, insofar as most people seem to have an intuitive disapproval of the practice.

However, this yields a rather different argument against cloning, not based in an emotional response, along the lines of: 'It seems wrong, so it probably is.' The data reported here indicate that the emotions and thoughts underlying negative judgements about cloning are varied and complex. Without pinpointing a specific emotion, like disgust, that is supposed to be a special source of wisdom on such topics, the intuitive reaction calls out for further analysis and explanation. We should presumably probe further to evaluate its source and reliability. ${ }^{23}$ For Kass and Kekes especially, disgust is marked out as a special kind of reaction that needs no further explanation to provide justification. In shifting away from disgust, the intuition would lose this special epistemic status, at least in the absence of further argument.

\section{Limitations}

This survey only provides a start to exploring the emotions people tend to feel towards human reproductive cloning. One potential limitation concerns the sample: the size is not extremely large and responses are from participants who are users of an online platform. However, studies of users of
Amazon's Mechanical Turk suggest that this group is more diverse and representative of the general population than the usual pool of undergraduate university students. ${ }^{24}$ Still, these data might not be generalisable to countries outside of the USA or North America.

Another potential limitation of this study is the exclusive use of self-reported emotions. However, self-report is not wholly unreliable or useless. While psychological research suggests that we are quite poor at understanding the reasons why we have certain mental states, there is less doubt that we have fairly reliable access to those states themselves, even if fallible. In their classic paper, Nisbett and Wilson ${ }^{25}$ themselves distinguish between content and process, noting that their research is compatible with our having special access to various states, including 'emotions, evaluations and plans' (255).

\section{Future research}

Acquiring data on emotional reactions to bioethical issues like cloning are especially useful for evaluating arguments that appeal to a particular emotional reaction that is supposed to be widespread. In this respect, we now have some initial data suggesting that a prominent argument from disgust against human reproductive cloning may rest on a dubious empirical assumption.

Future work might explore emotional reactions to other bioethical topics or individual differences among attitudes about cloning. Previous research suggests attitudes towards human cloning differ by political affiliation. Gallup indicates that, compared with Republicans, a slightly higher proportion of Democrats in the USA believe cloning human beings is morally acceptable. Related to this, Inbar $e t a^{26}$ found that conservatives are more disgust sensitive than liberals. Putting this together, it could be that those with conservative political beliefs make up most respondents who report feeling disgusted by human cloning, but further research is required before drawing firm conclusions.

Acknowledgements Thanks to Alberto Giubilini and Gregory Pence for comments.

Contributors JM is the sole contributor to this article.

Competing interests None declared.

Ethics approval The study was approved by the IRB at the University of Alabama at Birmingham (protocol X140826003).

Provenance and peer review Not commissioned; externally peer reviewed.

\section{REFERENCES}

1 Nisbet MC. Public opinion about stem cell research and human cloning. Public Opin Q 2004;68:131-54.

2 Shepherd R, Barnett J, Cooper $\mathrm{H}$, et al. Towards an understanding of British public attitudes concerning human cloning. Soc Sci Med 2007;65:377-92.

3 Riffkin R. New Record Highs in Moral Acceptability. Gallup Politics. http://www. gallup.com/poll/170789/new-record-highs-moral-acceptability.aspx (accessed Nov 2014).

4 Kass LR. The wisdom of repugnance: why we should ban the cloning of humans. New Repub 1997;216:17-26.

5 Kass LR. Preventing a brave new world: why we should ban human cloning now. New Repu 2001;224:30-9.

6 Kelly D. Yuck!: the nature and moral significance of disgust. Cambridge, MA: MIT Press, 2001.

7 Kekes J. A case for conservatism. Ithaca, NY: Cornell University Press, 1998.

8 Kahan DM. The progressive appropriation of disgust. In: Bandes S, ed. The passions of the law. New York: NYU Press, 1999:63-79.

9 Nussbaum MC. Hiding from humanity: disgust, shame, and the law. Princeton, NJ: Princeton University Press, 2004.

10 Pence GE. Who's afraid of human cloning? Lanham, MD: Rowman \& Littlefield 1998. 


\section{Reproductive ethics}

11 Laham S, Alter A, Goodwin G. Easy on the mind, easy on the wrongdoer: discrepantly fluent violations are deemed less morally wrong. Cognition 2009;112:462-6.

12 Schnall S, Haidt J, Clore GL, et al. Disgust as embodied moral judgment. Pers Soc Psychol Bull 2008;34:1096-109.

13 Eskine KJ, Kacinik NA, Prinz JJ. A bad taste in the mouth: gustatory disgust influences moral judgment. Psychol Sci 2011;22:295-9.

14 Pizarro D, Inbar $Y$, Helion C. On disgust and moral judgment. Emot Rev 2011;3:267-8.

15 May J. Does disgust influence moral judgment? Australas J Philos 2014;92:125-41.

16 May J. Repugnance as performance error: the role of disgust in bioethical intuitions. In: Clarke $\mathrm{S}$, et al, eds. The ethics of human enhancement: understanding the debate. New York: Oxford University Press, in press.

17 Giubilini A. What in the world is moral disgust? Australas J Philos 2015; in press.
18 Plutchik R. Emotion: a psychoevolutionary synthesis. New York: Harper \& Row, 1980.

19 Buhrmester M, Kwang T, Gosling SD. Amazon's mechanical turk: a new source of inexpensive, yet high-quality, data? Perspect Psychol Sci 2011;6:3-5.

20 Herz RS, Hinds A. Stealing is not gross: language distinguishes visceral disgust from moral violations. Am J Psychol 2013;126:275-86.

21 Gert J. Disgust, moral disgust, and morality. J Moral Philos 2015;12:33-54.

22 Haidt J. The righteous mind. New York: Pantheon, 2012.

23 Roache $\mathrm{R}$, Clarke S. Bioconservatism, bioliberalism, and the wisdom of reflecting on repugnance. Monash Bioeth Rev 2009;28:04.1-04.21.

24 Buhrmester et al. op. cit.

25 Nisbett RE, Wilson TD. Telling more than we can know: verbal reports on mental processes. Psychol Rev 1977;84:231-59.

26 Inbar Y, Pizarro DA, Bloom P. Conservatives are more easily disgusted than liberals. Cogn Emot 2009;23:714-25. 